\title{
Laser-assisted microdissection: a new tool for aquatic molecular parasitology
}

\author{
H. J. Small, J. Sturve, J. P. Bignell, M. Longshaw, B. P. Lyons, R. Hicks, \\ S. W. Feist, G. D. Stentiford*
}

Centre for Environment, Fisheries and Aquaculture Science (Cefas), Barrack Road, Weymouth, Dorset DT4 8UB, UK

\begin{abstract}
Laser-assisted microdissection (LMD) has been developed to isolate distinct cell populations from heterogeneous tissue sections, cytological preparations, or live cell samples. Downstream applications typically include gene expression studies using real-time PCR and array platforms, diagnostic PCR, and protein expression studies. LMD techniques are now commonplace in mainstream biological research and clearly have suitable applications in the field of aquatic pathology and parasitology. The present study used LMD to isolate 2 dinoflagellate parasites (Hematodinium spp.) from formalin-fixed paraffin-embedded tissue sections from 2 crustacean hosts, Cancer pagurus and Portunus trituberculatus. DNA was isolated from LMD parasite preparations, and partial regions (up to $300 \mathrm{bp}$ ) of the small subunit and the first internal transcribed spacer region of the rRNA gene complex from the Hematodinium spp. were PCR amplified using diagnostic primers. The amplification products were sequenced to confirm the identity of the targeted regions. The techniques, applications, and limitations of LMD to address questions in aquatic molecular pathology and parasitology are discussed.
\end{abstract}

KEY WORDS: Laser-assisted microdissection - Molecular parasitology - DNA · RNA · Aquatic parasitology

\section{INTRODUCTION}

There exist few methods for isolating small numbers of cells for genetic analysis, and an even smaller number of techniques for isolating protistan parasites, mainly because of their microscopic size, tissues they infect, and complexity of dissection. In addition, investigation of in situ host response to a pathogen (e.g. encapsulation) is challenging. Laser-assisted microdissection (LMD) has the potential to address these issues and allow researchers to harvest small numbers of cells for genetic and proteomic analysis. Essentially LMD provides a bridge between the pathology and molecular biology laboratory.

Originally developed for the analysis of tumor cells (Emmert-Buck et al. 1996), the LMD technique employed a focused infrared laser beam passed through a thermoplastic film adjacent to a routine tissue section mounted on a glass slide. The laser beam creates a 'melting effect' that temporarily attaches the cells of interest to the thermoplastic film, facilitating their removal (capture) from the remaining tissue section when the plastic film is raised. The selected cells are then processed for DNA and RNA extraction using standard methods modified for microscopic amounts of starting materials. Subsequently, several other LMD platforms have been developed, each with different methods of sample collection. An expanding literature base is evidence of their use in the mainstream biological sciences including cancer biology, pathology, and forensics (Fend \& Raffeld 2000, Player et al. 2004, Budimlija et al. 2005), and in a small number of parasitological investigations (Jones et al. 2004).

Potential applications of LMD to aquatic pathology and parasitological research include the isolation of parasites from host tissues, thereby enabling the subsequent extraction of parasite nucleic acids and protein. Using this approach it would be possible to microdissect parasites existing alone or in concert with identifiable organisms such as would occur in a mixed 
infection. PCR could be used to amplify phylogenetically informative regions in order to study the parasite's taxonomic relationships. This technique could also be used in combination with molecular diagnostics to aid in the identification of potential secondary hosts (if they exist) and investigate parasite life cycles. The analysis of parasite gene regulation is also of particular interest, and LMD coupled with molecular techniques would facilitate in vivo analysis of gene expression as opposed to culture-based techniques where parasites may act differently. This approach has been used in several studies of Plasmodium spp. isolated directly from host cells (Sacci et al. 2002, Semblat et al. 2002) and could potentially be used to investigate gene expression in parasites such as Perkinsus spp. from bivalve hosts, where several genes are thought to be involved in pathogenesis (Brown \& Reece 2003, Brown et al. 2005). LMD could also be applied to host-parasite interaction studies, thereby shedding light on the molecular machinery involved in host response events such as encapsulation (Pascual et al. 2006).

In this 'proof of principle' study, our objectives were to (1) amplify DNA from an important crustacean parasite (Hematodinium spp.) excised from archive formalin-fixed wax-embedded tissue sections via LMD; (2) compare 2 staining methods, a commercial kit and laboratory-based preparations of haematoxylin and eosin $(\mathrm{H} \& \mathrm{E}) ;$ and (3) assess the recovery of DNA and amplification of 2 target regions, small subunit ribosomal RNA (SSU) and the first internal transcribed spacer region of the ribosomal RNA gene complex (ITS1), commonly used for molecular diagnostics and taxonomy.

\section{MATERIALS AND METHODS}

Sample collection. Paraffin-embedded hepatopancreas samples from Hematodinium-infected edible crabs Cancer pagurus, sampled from Weymouth Bay in January 2004, were retrieved from the Centre for Environment, Fisheries \& Aquaculture Science (Cefas) Registry of Aquatic Pathology (www.aquaticpathology.co.uk). Tissues had previously been fixed in Davidson's seawater fixative for $24 \mathrm{~h}$ (Shaw \& Battle 1957), transferred to $70 \%$ industrial methylated spirit (IMS), followed by processing into wax in a vacuum infiltration processor. Fixed muscle samples of Hematodinium-infected Chinese swimming crabs Portunus trituberculatus were obtained from the Marine Fisheries Research Institute of Zhejiang, China. These samples were collected in 2006 and fixed in $10 \%$ neutral buffered formalin (NBF) for 24 to $48 \mathrm{~h}$ before transfer to $70 \%$ ethanol followed by embedding in paraffin. In both species of crab, diagnosis of Hematodinium sp. infection was made by prior analysis via H\&E stained sections. Positive control material for PCR (infected muscle tissues from both crab species preserved in $100 \%$ ethanol) was also obtained.

Section staining and laser microdissection. Paraffinembedded crab tissue sections were cut at $6 \mu \mathrm{m}$ on a rotary microtome, mounted onto membrane slides (Molecular Machines \& Industries), and air-dried. Sections from both crab species were stained using 2 different methods to compare staining characteristics and nucleic acid retrieval. The first involved an in-house H\&E staining procedure based on published protocols (Huang et al. 2002). Using this method, the membrane slides were first deparaffinized in 2 changes of xylene for $2 \mathrm{~min}$ each. The tissues were then rehydrated by incubation in a successive gradient of ethanols $(100 \%$, $95 \%, 95 \%$, and $70 \%$ ) for 1 min each before final equilibration in molecular grade water (free from DNase and RNase contamination). Slides were stained with Mayer's haematoxylin for $2 \mathrm{~min}$, rinsed in molecular grade water, and then blued in Scott's Tap Water (Surgipath) for $30 \mathrm{~s}$. The slides were then rinsed several times in molecular grade water followed by incubation in $70 \%$ ethanol for $30 \mathrm{~s}$. Slides were incubated in eosin for $1 \mathrm{~min}$, followed by incubation in $95 \%$ ethanol for $30 \mathrm{~s}, 100 \%$ ethanol for $1 \mathrm{~min}, 100 \%$ ethanol for $1 \mathrm{~min}$, and finally incubated in 2 changes of xylene for $2 \mathrm{~min}$ each. The membrane slides were subsequently air dried, inverted, and placed against a DNase-free glass slide for protection against contamination.

The second staining method utilized a commercially available staining kit (First Choice in LMD RNA friendly Basic Staining Kit, Molecular Machines \& Industries) following the manufacturer's protocol for paraffin sections. This kit was used on the basis that it may confer reduced nucleic acid degradation since the staining solutions are prepared for RNA recovery, which is more sensitive to histological staining procedures. After staining, the membrane slides were air dried and placed against a glass slide, as above.

LMD was performed using a mmi Cellcut system (Molecular Machines \& Industries) at the Cefas Weymouth laboratory. The system comprised an inverted microscope (Nikon) with a robotized stage attached to a digital camera, computer with panel monitor, and a fixed ultraviolet (cold) laser source. The sample was first viewed by light microscopy to identify the region of interest (tissue/parasite), which was then selected for excision using the laser. Microdissected samples were recovered (captured) by mechanically lowering and raising an adhesive isolation cap (attached to a $0.5 \mathrm{ml}$ collection tube) onto the membrane following laser cutting. Individually dissected samples were immediately resuspended in extraction buffer and processed for DNA extraction. 
DNA extraction and PCR. DNA was extracted from all microdissected samples using a QIAamp DNA Micro Kit (Qiagen) following the protocol for isolation of genomic DNA from laser-microdissected tissues. Carrier RNA was included or omitted for duplicate samples during the DNA extraction process to assess the influence of this step on DNA recovery (assessed by PCR). DNA was eluted in $15 \mu$ l of elution buffer. DNA from Cancer pagurus samples that were stained using both protocols (and also had the carrier RNA omitted during extraction) was quantified using a NanoDrop 1000 (Thermo Fisher Scientific). DNA from positive control materials was extracted using a DNeasy Blood and Tissue Kit (Qiagen) and eluted into $100 \mu \mathrm{l}$ elution buffer. All samples were immediately used for PCR after brief storage on ice.

Ribosomal RNA (rRNA) sequences were amplified from the extracted DNA samples using 2 previously published PCR assays for the detection of Hematodinium spp. (Gruebl et al. 2002, Small et al. 2007a). A 196 bp fragment of the SSU coding region was amplified from the Hematodinium sp. infecting Cancer pagurus using the following primers: Hemat-F-1487 5'-CCTGGCTCGATAGAGTTG-3' and Hemat-R-1654 5'-GGCTGCCGTCCGAATTATTCAC-3'. Additionally, a 298 bp fragment of the ITS1 spacer region was amplified from the Hematodinium sp. infecting Portunus trituberculatus using primers specific for detection of Hematodinium spp. infecting Callinectes sapidus, Liocarcinus depurator, and $P$. trituberculatus (HITS1F 5'-CATTCACCGTGAACCTTAGCC-3' and HITS1R 5' -CTAGTCATACGTTTGAAGAAAGCC-3') (Small et al. 2007a). Each $20 \mu$ reaction contained 1x Green GoTaq Flexi Buffer (Promega), $1.5 \mathrm{mM} \mathrm{MgCl}, 0.25 \mathrm{mM}$ of each dNTP, $1 \mu \mathrm{M}$ of each primer, 1 unit Taq polymerase, and $10 \mu$ l genomic DNA. For positive and negative control PCR reactions, $0.5 \mu \mathrm{l}$ of genomic DNA or water, respectively, was used. Amplifications were performed with an initial denaturation of $94^{\circ} \mathrm{C}$ for $4 \mathrm{~min}$, followed by 40 cycles at $94^{\circ} \mathrm{C}$ for $30 \mathrm{~s}$, $56^{\circ} \mathrm{C}$ for $30 \mathrm{~s}, 72^{\circ} \mathrm{C}$ for $1 \mathrm{~min}$, with a final elongation step at $72^{\circ} \mathrm{C}$ for $5 \mathrm{~min}$. Following amplification, $10 \mu \mathrm{l}$ of each PCR product were analysed by agarose gel electrophoresis $(2 \% \mathrm{w} / \mathrm{v})$, stained with ethidium bromide, and viewed under a UV light source. Images were captured with a Gel Doc 2000 (Bio Rad) imaging system.

Sequencing and analysis. Amplification products of 196 and $298 \mathrm{bp}$ were excised from the agarose gel using a sterile scalpel blade and purified using a QIA quick Gel Extraction Kit (Qiagen). Bands from 2 independent PCR products for each target (SSU and ITS1) were excised and purified. Puri- fied amplification products were bidirectionally sequenced using a Big Dye Terminator v3.1 Cycle Sequencing Kit (Applied Biosystems) following the standard manufacturer's protocol. Thermocycling parameters were as follows: 30 cycles of $94^{\circ} \mathrm{C}$ for $30 \mathrm{~s}$, $96^{\circ} \mathrm{C}$ for $10 \mathrm{~s}, 50^{\circ} \mathrm{C}$ for $10 \mathrm{~s}, 60^{\circ} \mathrm{C}$ for $4 \mathrm{~min}$, followed by a final incubation at $4^{\circ} \mathrm{C}$. The sequencing products were precipitated using ethanol/sodium acetate and resuspended in $20 \mu \mathrm{l} \mathrm{Hi-Di}$ formamide (Applied Biosystems) and electrophoresed on an ABI 3100 Avant Prism genetic analyser (Applied Biosystems).

The Hematodinium rRNA sequences were constructed from the forward and reverse sequencing reactions using Sequencher (v4.2). Primer sequences were removed from the $5^{\prime}$ and $3^{\prime}$ ends and the resulting 4 sequences compared for similarity to other Hematodinium sp. in GenBank using the Basic Local Alignment Search Tool (BLAST) (Altschul et al. 1990).

\section{RESULTS}

\section{LMD and DNA extraction}

Wax embedded sections of Hematodinium-infected muscle and hepatopancreas tissues from Cancer pagurus and Portunus trituberculatus were successfully sec-

Table 1. Cancer pagurus. Quantification (ng $\left.\mu^{-1}\right)$ of DNA extracted from Hematodinium parasites infecting C. pagurus. Sections were stained using either a First Choice in LMD RNA friendly Basic Staining Kit following the recommended protocol, or an H\&E-based protocol (see 'Materials and methods'). DNA was extracted using a QIAamp DNA Micro Kit (carrier RNA omitted). LMD: laser-assisted microdissection

\begin{tabular}{|lcc|}
\hline LMD area & $\begin{array}{c}\text { First Choice } \\
\text { Staining Kit }\end{array}$ & H\&E \\
\hline $400 \times$ field of view $\left(86020 \mu^{2}\right)$ & 1.8 & 1.7 \\
$1 / 2400 \times$ field of view $\left(43010 \mu^{2}\right)$ & 1.3 & 1.4 \\
$1 / 4400 \times$ field of view $\left(21505 \mu^{2}\right)$ & 1.3 & 1.2 \\
\hline
\end{tabular}
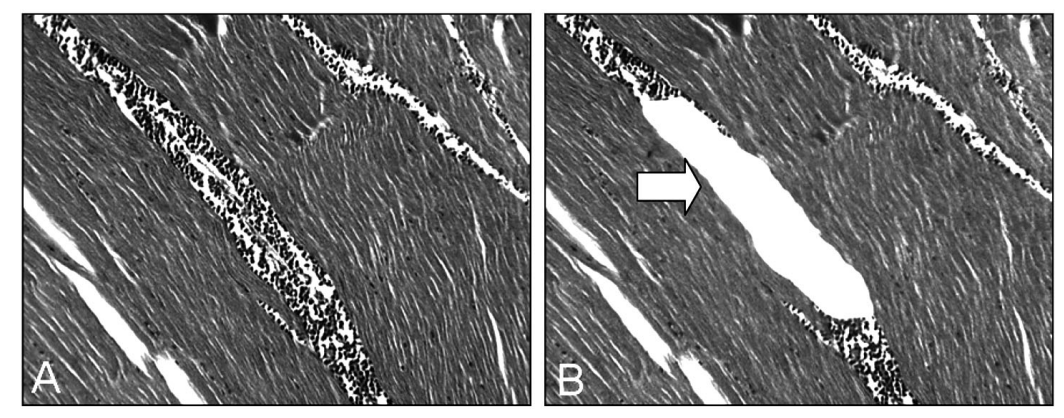

Fig. 1. Portunus trituberculatus. Sections of Hematodinium-infected muscle tissues (A) before and (B) after laser-assisted microdissection (LMD). Arrow: parasites removed from between the muscle fibers. H\&E stained, $\times 200$ magnification 
tioned onto membrane slides and stained using both protocols. There was little observable difference in staining characteristics between the 2 protocols, with both nuclear and cytoplasmic structures of host and parasite clearly stained. The sections of C. pagurus hepatopancreas were from an advanced infection, where masses of parasitic plasmodial cells filled the dilated haemal sinuses (Stentiford et al. 2002). The intensity of infection allowed excision of parasites (by LMD) from a $400 \times$ field of view $\left(86020 \mu^{2}\right), 1 / 2400 \times$ field of view $\left(43010 \mu^{2}\right)$, and $1 / 4400 \times$ field of view (21505 $\mu^{2}$, approximately 50 parasites). The muscle sections from $P$. trituberculatus were also from an advanced infection, and allowed for dissection of parasites from between muscle fibers (Fig. 1). The quantification of extracted DNAs indicated that both staining protocols were comparable, and that recovery was correlated with starting tissue sample size (Table 1).

\section{PCR and sequencing}

Both the SSU and ITS1 regions were successfully amplified using template DNAs extracted from LMD parasite material (Fig. 2). Absolute sensitivity was not investigated; however, DNA extracted from 1/4 400× field of view produced a strong PCR amplification
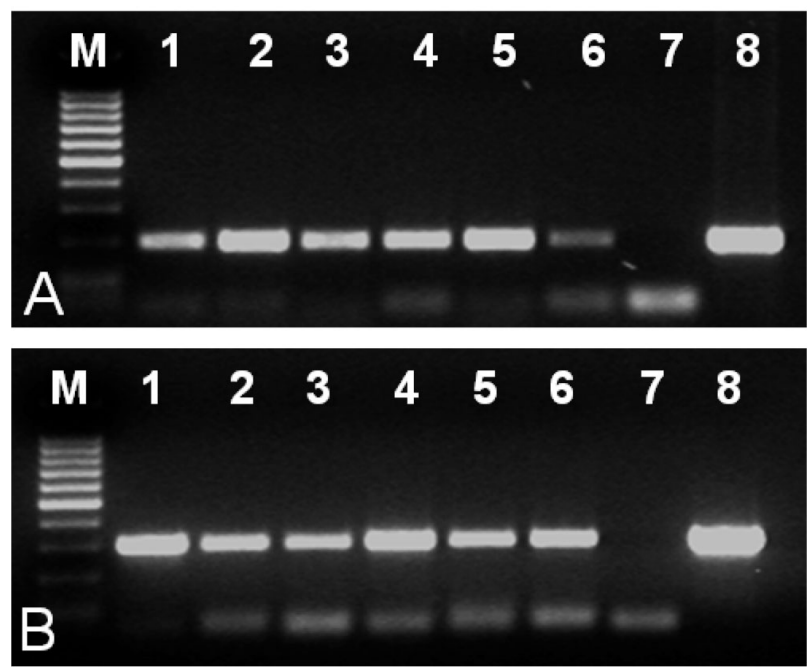

Fig. 2. Cancer pagurus and Portunus trituberculatus. PCR amplification of Hematodinium rDNA regions from LMD samples. (A) PCR amplification of the SSU region from the Hematodinium sp. infecting C. pagurus. (B) PCR amplification of the ITS1 region from the Hematodinium sp. infecting $P$. trituberculatus. Lanes 1-3: DNA template material extracted (carrier RNA included) from $400 \times, 1 / 2400 \times$, and $1 / 4400 \times$ fields of view. Lanes 4-6: DNA template material extracted (carrier RNA omitted) from $400 \times, 1 / 2400 \times$, and $1 / 4400 \times$ fields of view. Lane 7: negative control (no template). Lane 8: positive control (DNA extracted from ethanol preserved parasite material). M: 100 bp molecular weight marker band for both the SSU and ITS1 regions (Fig. 2, lanes 3 and 6). Slight variation was observed in the PCR band intensities, and in the case of the Cancer pagurus quantified material, the PCR band intensities (Fig. 2A, lanes 4 to 6) were associated with the initial DNA quantification results. In addition, PCR band intensities of the SSU amplification reactions using DNA templates from the excised $1 / 4400 \times$ field of view (Fig. 2A, lanes 3 and 6) indicated that inclusion of the carrier RNA during DNA extraction resulted in an increased recovery of amplifiable target DNA.

Both SSU and ITS1 amplification fragments sequenced were identical within each targeted locus. BLAST comparison of the SSU consensus sequence from the Hematodinium sp. infecting Cancer pagurus revealed a $100 \%$ similarity to Hematodinium spp. infecting Carcinus maenas and Liocarcinus depurator. The ITS1 consensus sequence from the Hematodinium sp. infecting Portunus trituberculatus also revealed a high similarity to other Hematodinium spp. sequences in GenBank (99 to $100 \%$ similarity to previously submitted Hematodinium sp. ITS1 sequences from $P$. trituberculatus, and a $97 \%$ similarity to the Hematodinium sp. infecting Liocarcinus depurator).

\section{DISCUSSION}

In the present study we isolated Hematodinium spp. parasites from archive tissue sections using LMD. We subsequently extracted DNA from this paraffin embedded material and amplified DNA sequences up to $298 \mathrm{bp}$ in length from Hematodinium spp. SSU and ITS1 rRNA regions. Results demonstrate the potential of LMD in molecular diagnostics and in the genotyping of aquatic animal parasites. LMD provides a significantly improved link between the molecular diagnostic and pathology laboratory by allowing for accurate selection of particular cells for nucleic acid characterization. Methodological considerations and potential applications of LMD in the field of aquatic disease diagnostics are discussed below.

Successful molecular analysis of nucleic acids recovered from LMD samples necessitates that all steps in the tissue sampling process are adequately controlled since each stage influences subsequent steps, and ultimately the value of data recovered. In the present study we employed 2 protocols to stain tissue sections, both based on the use of Mayer's H\&E to visualize cell nuclei and cytoplasmic features. These dyes are commonly used in routine histological staining to identify parasites. There were no significant differences in cellular staining characteristics or DNA yield between the 2 methods used, and we suggest that due to the high cost per sample when using commercial kits, laborato- 
ries can utilize their own stains and either follow published staining protocols for laser microdissected materials (Huang et al. 2002) or develop their own.

Methods used to isolate parasite DNA from paraffinembedded tissue sections have previously involved the manual dissection of infected tissues of interest from deparaffinized sections (unstained, mounted on glass slides) using a sterile scalpel blade (Vachot \& Monnerot 1996), and the microdissection of parasites from stained sections using manual microdissection procedures (Shen et al. 2001). DNA is subsequently extracted and purified from the dissected tissues of interest using Proteinase K digestion and phenol-chloroform/ethanol precipitation procedures. Both these techniques work well when used on tissues with high parasite burdens or large parasites, but lack precision when isolating parasite material, as host tissues are routinely carried over into the DNA extraction step, potentially confounding downstream results. In addition, a 'host swamping' effect can occur when trying to isolate parasite DNA from infected tissues, in which host DNA accounts for the majority of the DNA extracted, reducing the amount of parasite template available for subsequent molecular analysis. LMD techniques have the ability to substantially reduce contaminating host nucleic acids from parasite preparations, thus improving downstream analysis of parasite material. The mmi Cellcut system used in the present study employs a membrane slide and an adjacent glass slide to effectively 'sandwich' the specimen, thus, protecting it from contaminants. In addition, when microdissected material is removed from the tissue section, the cap makes contact with the membrane only, preventing contamination from surrounding (non-target) tissues.

In the present study parasite DNA was isolated and amplified from infected tissues that were initially formalin-fixed (Davidson's for $24 \mathrm{~h}$ and $10 \%$ NBF for 48 to $72 \mathrm{~h}$ ). Formalin-based fixatives are known to cross-link DNA and proteins, historically resulting in low quality, highly degraded nucleic acids. Certainly, RNA would be significantly degraded; nevertheless, recovery of amplifiable DNA from formalin fixed material is possible, with success appearing dependent on whether the formalin solution was buffered, the temperature of tissue incubation, and the time of incubation in formalin (Hamazaki et al. 1993, Koshiba et al. 1993, Miething et al. 2006). A number of commercial companies now produce kits specifically tailored for extraction of nucleic acids from minute samples including those from LMD. We extracted DNA from all microdissected samples using a Qiagen spin-column-based kit in an attempt to standardize all extractions. The variability of DNA recovered from different sized starting samples (Table 1) is likely explained by a combination of the following: (1) samples were on the published limit of detection of the quantification equipment, and (2) all of the microdissected tissue may not have been fully recovered from the adhesive cap into the extraction buffer. It is worth noting that nucleic acids absorbed onto the membranes of spin columns are never fully recovered in the elutant, and for downstream applications that require maximum DNA and RNA recovery other extraction techniques (such as phenol/chloroform or Trizol) may be more appropriate.

Significantly, we were able to amplify $196 \mathrm{bp}$ of the SSU and $298 \mathrm{bp}$ of the ITS1 rRNA regions from both Hematodinium spp., and although not attempted in the present study, it may be possible to amplify larger targets from LMD material. In addition to being a target for diagnostics, regions of the SSU and ITS rRNA are regularly used in taxonomic studies of many aquatic parasites (Le Roux et al. 2001, Dungan \& Reece 2006). ITS1 has previously been used to differentiate between closely related Hematodinium spp. infecting a number of hosts (using primers HITS1F and HITS1R also used in the present study, see Small et al. 2007a) or confirm a single infective species (Small et al. $2007 \mathrm{~b}$ ); if required, it would be possible to use LMD and targeted PCR to amplify further phylogenetically informative regions. This application could be repeated for numerous other aquatic parasites where the diagnostic PCR primers amplify a small fragment.

LMD has the potential to allow researchers to isolate specific pathogens from tissues with mixed infections. Recently, Bonamia exitiosa was found co-infecting (with B. ostreae) the European flat oyster Ostrea edulis in Spain, and is the first report of this parasite in European waters (Abollo et al. 2008). B. exitiosa is listed by The Office International des Epizooties (OIE) as a notifiable disease. Since many pathology archives contain material used to make yearly assessments of the disease status of fish and shellfish (mainly by standard histopathology unless required otherwise), one possible scenario would be to analyze archive oyster pathology sections using LMD to isolate parasite cells for molecular analysis to confirm species identity. This approach would offer significantly enhanced resolution for species identification in historical material. In the case of oysters, this approach would be assisted by the fact that $B$. ostreae and $B$. exitiosa can be distinguished in histological sections according to size ( $B$. ostreae producing a smaller microcell stage). However, not all parasites in mixed infections have different morphological features and, therefore, it can be extremely difficult to distinguish between parasites using traditional light microscopy of stained histological sections (e.g. Haplosporidium costale and H. nelsoni infecting Crassostrea virginica, see Stokes \& Burreson 2001). In these cases other methods such as immunohistochemistry or the application of DNA 
probes may be required to distinguish closely related pathogens (Stokes \& Burreson 2001). Another potential use for historical archive LMD material (that is difficult to aquire) would be in microsatellite-based population genetic studies. Microsatellites are seldom larger than $300 \mathrm{bp}$ (including primers) and amplifications require comparable quantities of DNA as standard PCR, thus microsatellites could be amplified from LMD material (Chistiakov et al. 2006).

Acknowledgements. We thank W. J. Xu (Marine Fisheries Research Institute of Zhejiang) for the samples of Hematodinium-infected Portunus trituberculatus. We also thank R. Carnegie and J. Moss for their helpful critique of the manuscript. This work was supported under Cefas contract DP195 to G.D.S.

\section{LITERATURE CITED}

Abollo E, Ramilo A, Casas SM, Comesaña P, Cao A, Carballal MJ, Villalba A (2008) First detection of the protozoan parasite Bonamia exitiosa (Haplosporidia) infecting flat oyster Ostrea edulis grown in European waters. Aquaculture 274:201-207

Altschul SF, Gish W, Miller W, Myers EW, Lipman DJ (1990) Basic local alignment search tool. J Mol Biol 215:403-410

Brown GD, Reece KS (2003) Isolation and characterization of serine protease gene(s) from Perkinsus marinus. Dis Aquat Org 57:117-126

Brown GD, Kaattari SL, Reece KS (2005) Effect of homogenate from different oyster species on Perkinsus marinus proliferation and subtilisin gene expression. J Shellfish Res 24:1027-1033

Budimlija ZM, Lechpammer M, Popiolek D, Fogt F, Prinz M, Bieber FR (2005) Forensic applications of laser capture microdissection: use in DNA-based parentage testing and platform validation. Croat Med J 46:549-555

Chistiakov DA, Hellemans B, Volckaert FAM (2006) Microsatellites and their genomic distribution, evolution, function and applications: a review with special reference to fish genetics. Aquaculture 255:1-29

> Dungan CF, Reece KS (2006) In vitro propagation of two Perkinsus spp. parasites from Japanese manila clams Venerupis philippinarum and description of Perkinsus honshuensis n. sp. J Eukaryot Microbiol 53:316-326

Emmert-Buck MR, Bonner RF, Smith PD, Chuaqui RF and others (1996) Laser capture microdissection. Science 274: 998-1001

Fend F, Raffeld M (2000) Laser capture microdissection in pathology. J Clin Pathol 53:666-672

Gruebl T, Frischer ME, Sheppard M, Neumann M, Maurer A, Lee RF (2002) Development of an 18S rRNA gene-targeted PCR-based diagnostic for the blue crab parasite Hematodinium sp. Dis Aquat Org 49:61-70

Hamazaki S, Koshiba M, Habuchi T, Takahashi R, Sugiyama $T$ (1993) The effect of formalin fixation on restriction

Editorial responsibility: Catherine Collins,

Aberdeen, UK endonuclease digestion of DNA and PCR amplification. Pathol Res Pract 189:553-557

Huang LA, Luzzi V, Ehrig T, Holtschlag V, Watson MA (2002) Optimized tissue processing and staining for laser capture microdissection and nucleic acid retrieval. Methods Enzymol 356:49-62

Jones MK, Randall LM, McManus DP, Engwerda CR (2004) Laser microdissection microscopy in parasitology: microscopes meet thermocyclers. Trends Parasitol 20:502-506

Koshiba M, Ogawa K, Hamazaki S, Sugiyama T, Ogawa O, Kitajima T (1993) The effect of formalin fixation on DNA and the extraction of high-molecular-weight DNA from fixed and embedded tissues. Pathol Res Pract 189:66-72

> Le Roux F, Lorenzo G, Peyret P, Audemard C and others (2001) Molecular evidence for the existence of two species of Marteilia in Europe. J Eukaryot Microbiol 48: 449-454

Miething F, Hering S, Hanschke B, Dressler J (2006) Effect of fixation to the degradation of nuclear and mitochondrial DNA in different tissues. J Histochem Cytochem 54: 371-374

> Pascual S, Abollo E, Azevedo C (2006) Host-parasite interaction of a muscle-infecting didymozoid in the Atlantic mackerel Scomber scombrus L. ICES J Mar Sci 63: 169-175

> Player A, Barrett JC, Kawasaki ES (2004) Laser capture microdissection, microarrays and the precise definition of a cancer cell. Expert Rev Mol Diagn 4:831-840

Sacci JB, Aguiar JC, Lau AO, Hoffman SL (2002) Laser capture microdissection and molecular analysis of Plasmodium yoelii liver-stage parasites. Mol Biochem Parasitol 119:285-289

Semblat JP, Silvie O, Franetich JF, Hannoun L, Eling W, Mazier D (2002) Laser capture microdissection of Plasmodium falciparum liver stages for mRNA analysis. Mol Biochem Parasitol 121:179-183

Shaw BL, Battle HI (1957) The gross microscopic anatomy of the digestive tract of the oyster Crassostrea virginica (Gmelin). Can J Zool 35:325-347

Shen DF, Herbort C, Tuaillon N, Buggage RR, Egwuagu CE, Chan CC (2001) Detection of Toxoplasma gondii DNA in primary intraocular B-Cell lymphoma. Mod Pathol 14: 995-999

Small HJ, Shields JD, Hudson KL, Reece KS (2007a) Molecular detection of the Hematodinium sp. infecting the blue crab, Callinectes sapidus. J Shellfish Res 26:131-139

Small HJ, Shields JD, Moss JA, Reece KS (2007b) Conservation in the first internal transcribed spacer region (ITS1) in Hematodinium species infecting crustacean hosts found in the United Kingdom and Newfoundland. Dis Aquat Org 75:251-258

Stentiford GD, Green M, Bateman K, Small HJ, Neil DM, Feist SW (2002) Infection by a Hematodinium-like parasitic dinoflagellates causes pink crab disease (PCD) in the edible crab Cancer pagurus. J Invertebr Pathol 79: 179-191

Stokes NA, Burreson EM (2001) Differential diagnosis of mixed Haplosporidium costale and Haplosporidium nelsoni infections in the eastern oyster, Crassostrea virginica, using DNA probes. J Shellfish Res 20:207-213

Vachot AM, Monnerot M (1996) Extraction, amplification and sequencing of DNA from formaldehyde-fixed specimens. Ancient Biomol 1:3-16

Submitted: May 9, 2008; Accepted: September 13, 2008

Proofs received from author(s): November 11, 2008 